\title{
SHOULD I STAY, OR SHOULD I GO? REVISITING STUDENT RETENTION MODELS IN DISTANCE EDUCATION
}

\author{
Dr. Marko RADOVAN \\ ORCID: 0000-0002-6564-9201 \\ Faculty of Arts, University of Ljubljana \\ Ljubljana, Slovenia
}

Received: 06/09/2018 Accepted: 02/11/2018

\begin{abstract}
Supporters of distance education highlight the many advantages of online learning as compared to face-toface education, such as greater openness, diversity of teaching materials, adjustment to student learning styles, the speed of learning, and more. Despite the advantages, the growing number of programs, and the increased acceptance of distance education in national strategies worldwide, distance learning providers are faced with the problem of dropouts. Studies have shown that the dropout rate in distance educational programs is higher than the dropout rate in traditional programs. Understanding of the reasons and determinants behind dropping out of an educational program is a challenging task for educators, researchers, and policymakers. In this paper, we describe the main characteristics of distance education, and analyze the models that try to describe and prevent students from dropping out of these programs. Our analysis suggests that the circumstances that affect the dropout rate should be considered in the planning and implementation of distance education programs.
\end{abstract}

Keywords: Distance education, dropout, retention models, information and communication technologies in education.

\section{INTRODUCTION}

Distance education is becoming an increasingly important part of education. It deals with a growing number of educational institutions, especially those that exercise methods of training employees in companies, public administrations, and other organizations. Tait and Mills (1999) argue that distance learning has flourished so much because of the rapid economic, social, and political change, mainly due to the rapid development of information technology. The need to adapt to changes in these areas has resulted in high demand for further education. Thus, the educational institutions allow more students (or participants) to enroll into their programs; even businesses and other organizations have an easier and cheaper way to train their staff.

In the last few decades, distance education became most established in the United States, where online learning is, primarily, a first-class business opportunity that brings high profits. The US distance education market is estimated at $\$ 27$ billion (Docebo, 2018, p. 4), representing a 16\% share in the global market. It is also becoming a model for education, expanding in the form of so-called "corporate universities" - training enterprises, set up by large corporations, that provide training by following the educational needs of these organizations (Liu, Huang, \& Wosinski, 2017).

Distance education is also finding a prominent place in the strategic documents of the European Union. The European Commission has already highlighted the potential of Information and communications technology (ICT) in reaching the EU's basic strategic goal, namely to become the most competitive, knowledge-based society in the Lisbon Strategy (Commission of the European Communities, 2000). The role of ICTs, and ways to use them to achieve the underlying strategic goals that were later outlined in several documents: the eEurope, 2002, and eEurope, 2005, Action Plans, continued by the i2010 Strategy PaperEuropean Information Society, 2010. In 2009, an "Education and Training 2020" work program (ET2020) 
was adapted, which should serve as a forum for the exchange of best practices, information, and advice on political reforms between Member States, the Commission, and educational institutions. The "ET 2020 Strategic Framework" covers all forms of learning at all levels of lifelong learning, and it highlights education as the main drive for smart, sustainable, and inclusive growth. This initiative puts forward an open and competitive digital economy, highlighting ICT as the key facilitator of social inclusion and quality of life.

As has already been found in many studies, the dropout rate from education is a serious problem, both on a systemic and personal level. The financial aspect is certainly linked to an investment in higher education, which is mostly publicly funded in the EU (OECD, 2017). Of course, we must emphasize that financial costs are only part of all "costs" of the dropout rate. More important, and often more persistent, are the emotional/affective consequences of discontinuing education. These are more difficult to measure, but they are more important from the point of view of the individual.

Our emphasis in the article will be that dropping out is a multi-dimensional phenomenon, and that before introducing various measures it is necessary to, first, adequately define it, and then to analyze the causes that lead to the interruption of education. One of the most important authors who first presented the complexity of this phenomenon is Vincent Tinto (1975). Tinto emphasizes the importance of creating a good definition of drop-out, which he considers important in determining the reasons that led to it. Lee and Choi (2011), who reviewed the research in the field of dropout, also concluded that authors focus primarily on the analysis of the causes, and less on the definition of the concept itself.

Reducing student drop outs is not only important for the university leaders but, according to Tinto (2006), it is one of the most studied areas in higher education. Despite several decades of research in this area (Spady, 1971; Bean \& Metzner, 1985; Carr, 2000; Simpson, 2003; Herbert, 2006), no significant progress has been made. It certainly means that it is a topic that needs to be explored further. Van Ameijde, Weller, and Cross (2016) made a step forward in this regard. The ICEBERG model, based on the analysis of empirical research, is composed of seven main principles that can help reduce early school leaving.

\section{GENERATIONS OF DISTANCE EDUCATION}

Online learning is the last stage of distance education development. We find the first rudiments of distance education in the early 18th century; at that time, the development of postal services and printed material allowed independent, self-directed learning for people in remote places, such as some in North America. Distance learning meant that students didn't have to attend classical, geographically-distant educational institutions. On a larger scale, the distance education started to expand in the second half of the nineteenth century when, in the United States, Canada, Australia, Sweden, Germany, and the UK, the system of socalled correspondence education began to prosper. Methods and ways of learning were, of course, dependent on the level of education and technology development. In general, it can be said that from the very beginnings of distance education, the format developed and enforced the use of new pedagogical approaches and strategies. From the pedagogical point of view, it can be argued that distance education is mainly based on the needs of the individual learner. It emphasizes greater flexibility regarding speed, space, content, and study time. Teachers' roles in such situations are of an advisory and guiding nature (Makovec, 2018; Simonson, Smaldino, \& Zvacek, 2015).

- In distance learning, the following are particularly emphasized:

- An active and central role of the student in the learning process;

- The important role of study aids in the learning process;

- The use of different (active) teaching and learning methods;

- Communication takes place primarily in discussion forums, blogs, wikis, and e-mails.

The basic characteristics of distance education, therefore, mean that it is an educational process in which the teacher and student are spatially separated. Teaching is a process that happens remotely from the student. This removes some of the inhibiting factors imposed by traditional education, such as compulsory participation in classroom classes at a precise time, etc. This also changes the teacher's role, primarily by providing knowledge to participants indirectly, with the help of learning aids, such as printed materials, multimedia materials, computer and web applications, and the like. At the same time, this also changes the 
role of an educational institution, which has to devote more time and effort than before to the planning and production of teaching materials and to providing various forms of assistance to the participants.

Perhaps even more important than the free choice of teaching materials its advantage is to motivate students to be able to choose their way of learning. Marland (1997) believes that the active participation of students in education encourages interest in learning and, thus, contributes to a better evaluation of knowledge. In psychological theories of motivation, this principle is well known. When we speak of free choice of learning mode, we mean freedom to select different resources, time, and speed of learning, in which the participant wins a piece of true knowledge. Some have a better memory of when they hear information, some when they read aloud; still others need to sketch, get a rough overview, and later acquire knowledge. All in all, the modes of learning that are most appropriate for different individuals are countless. It is true that everyone finds their own learning style, one that allows them to make learning more efficient.

Some authors believe that the concept of distance learning can be developed only with the notion of "open" education, which will allow students to have more influence and autonomy in learning (Lee, Pate, \& Cozart, 2015). Flexibility in the selection of the place of learning, the possibility of choosing the method of study, greater diversity of learning materials, dialogue, and a move towards more individual learning are also stressed (Peters, 2001). In face-to-face education, we do not have many options to choose from that guide the way we learn because the teacher must adapt to various factors (student, study requirements, the context in which learning takes place, etc.). This is precisely the advantage of distance learning; it enables the use of a wide range of methods, according to the participant's choice.

\section{DROPOUT RATES FROM DISTANCE EDUCATION}

Despite the growing number of distance education programs, and substantial interest among potential students to learn online, distance education providers are also faced with the problem of dropouts, which is one of the major concerns of organizations that provide this type of education. Studies show that the dropout rate in education programs conducted in the form of online learning, is higher than in traditional programs (Bawa, 2016; Carr, 2000; Diaz, 2002; Flood, 2002; Parker, 1999; Simpson, 2004, 2013), and studies show that they are an even more severe problem in MOOCs - Massive Open Online Courses (Gomez-Zermeno \& Aleman de La Garza, 2016). High dropout rates in distance education can be seen as a weakness, but also as a special feature which should be considered in the planning and implementation of educational programs that are running in e-classrooms. Diaz (2002) believes that there are multiple factors that influence students to drop their classes, e.g. student characteristics (i.e., demographics), the quality of the class or its instruction, the course discipline, socioeconomic factors, apathy, etc. Some reasons are difficult for institutions to address (such as a lack of finance), while others that occur on a more personal level (motivation, digital skills, etc.) are within institutions' reaches and should certainly be addressed.

The issue of dropout rates and successful completion of education has been an important topic for a long time. In recent years, with the expansion of distance education, this issue gained momentum and context within studies - to understand the circumstances that lead to interruptions in education processes. Information regarding dropouts is very different. Some argue that, in some programs that are carried out as distance education, the dropout rate is around $70 \%$ to $80 \%$ (Flood, 2002). Parker (1999) states that the dropout rate is higher than $40 \%$, Diaz (2002) believes it to be $20 \%$ to $50 \%$, Carr (2000) that the dropout rate in education programs at a distance are $10 \%$ to $20 \%$ higher in comparison to traditional classes (Herbert, 2006). Similarly, Simpson (2013) reports that in a program that has both a distance and a face-to-face mode, graduation rates are four time higher in the face-to-face mode (Simpson, 2013, p. 106). As noted in Bawa's (2016) review of previous studies, "online courses have several social, technological, and motivational issues existing from both the learners' and the faculty's perspectives" (Bawa, 2016, p. 1).

Until recently, it was believed that the dropout rate was mainly a result of the social and economic conditions in which students live. But in recent years, there is a growing conviction that the dropout rate is also a problem of educational institutions, and that it depends on preventive measures to reduce the dropout rate. The dropout rate is ultimately also an economic problem, not just an educational one. When calculating the cost of educational and financial structures, the number of program participants is considered. If the latter is drastically reduced, the program cannot be implemented. 


\section{MODELS OF STUDENT RETENTION}

In continuation, some theories and theoretical models that have dealt with the issues of dropouts will be presented. Among the most influential are Tinto's integrative model (1975), Bean-Metzner's model of student dropout (1985), Kember (1989), Rovai (2003), and Park (2007) .

The "mother of all retention models" is Tinto's (1975) "Student Integration Model." Tinto's model is based on the strategies by which institutions can increase and sustain participation in the study. Tinto (1975) points out that dropout from education is a long-lasting process, which is mainly characterized by the interaction and the congruency between an individual and the institution (where the individual gets education, sets personal goals, develops aspirations etc.), and subsequently leads to a decision to continue or abandon education. Tinto is convinced that the decisive factor that affects the progression of an individual's education is correlated with emotional connections to other students and the educational institution in which they are studying.

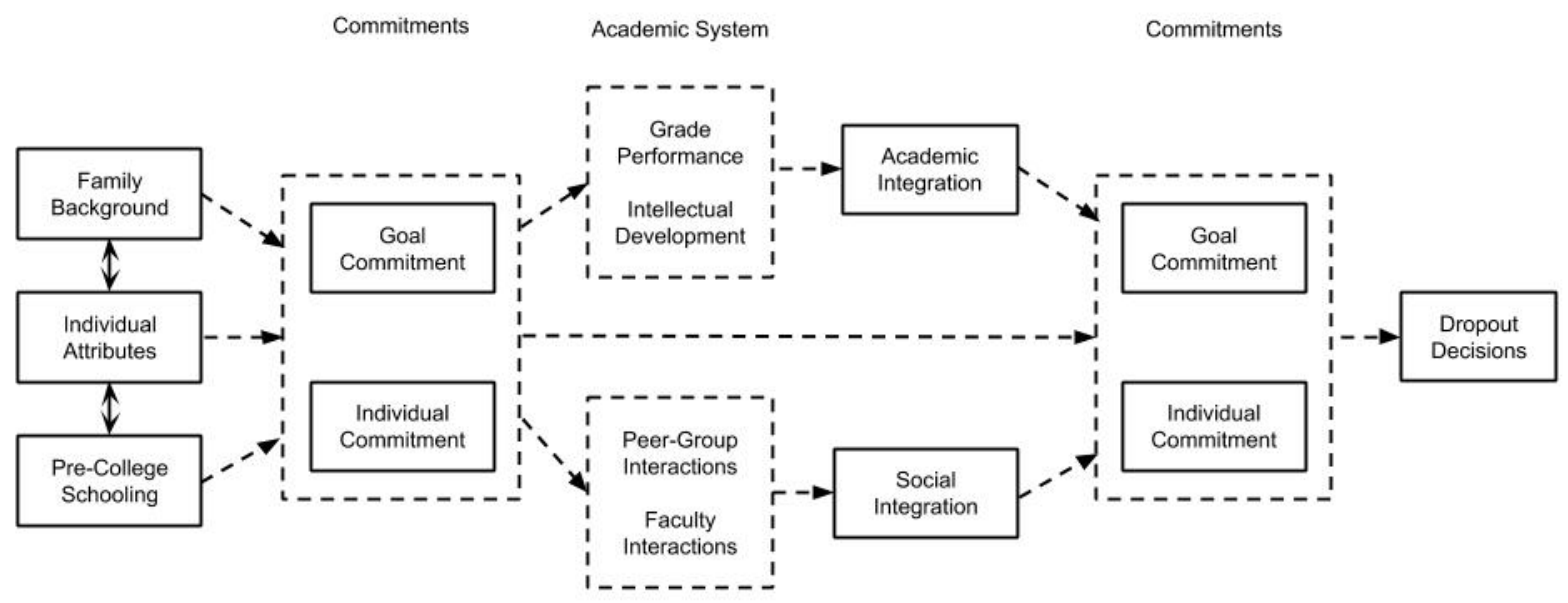

Figure 1. Student Integration Model (Tinto, 1975)

Despite its importance, however, Tinto's model for the study of dropouts from distance education is not the most appropriate, since his model is designed especially with respect to the regular (face-to-face) students under 25 years of age who are living in the campus. The impact of institutional integration is less important for older participants, who are not staying in the school and, therefore, don't spend time together, or find themselves less connected to the institution. His model does not consider the impact of various external factors that are important for understanding the persistence of exceptional students in distance learning (Bean \& Metzner, 1985; Rovai, 2003). Even Tinto himself has pointed out that the model should be modified when applied to part-time students (Tinto, 1975).

From the standpoint of compliance with the characteristics of adult learners, Bean and Metzner (1985) have made a step forward. They developed a conceptual model with which they tried to explain the dropouts of adult ("non-traditional”) students. 


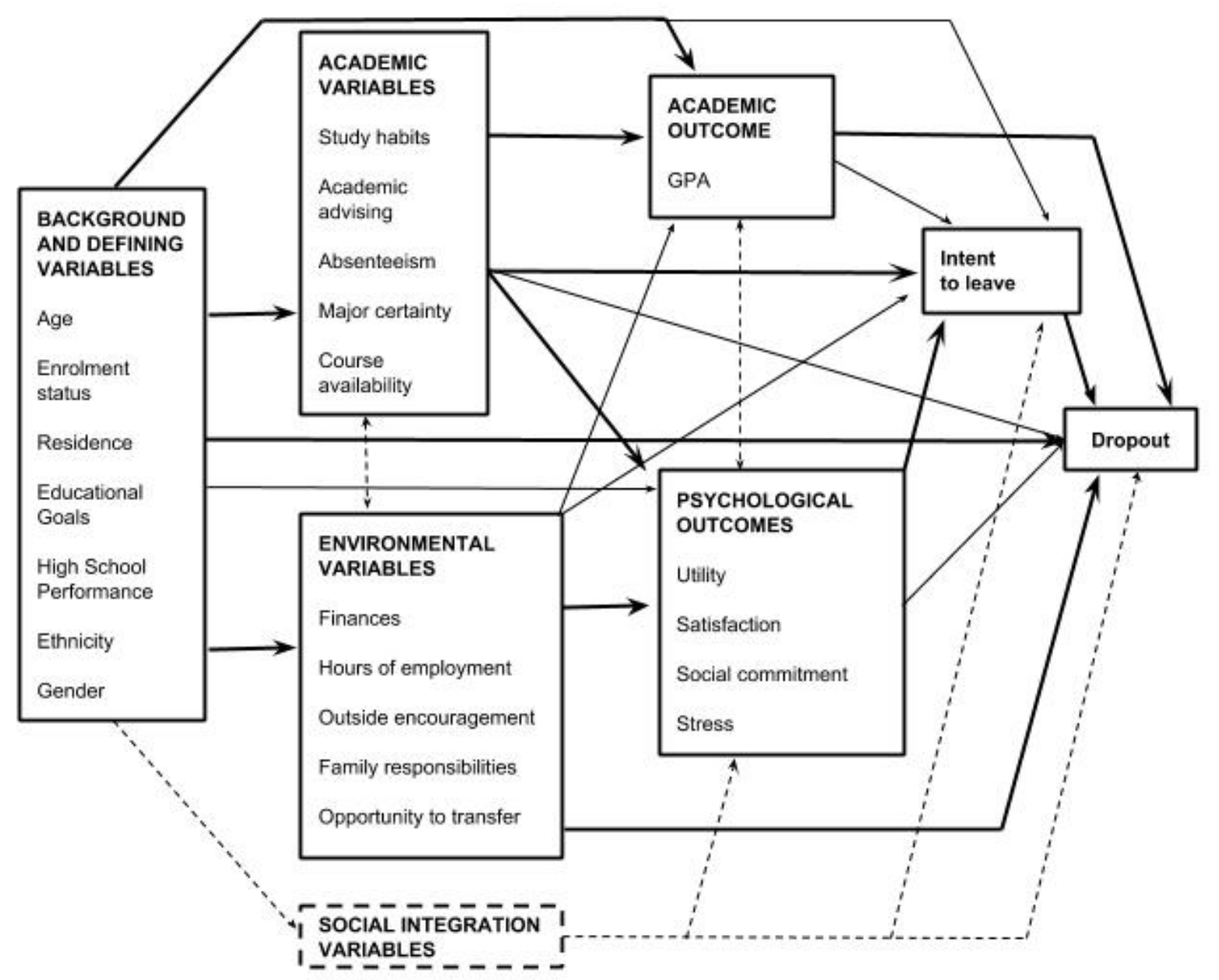

Figure 2. A Conceptual model of non-traditional student attrition (Bean \& Metzner, 1985)

Bean \& Metzner argued that the structure of support of this population is different from populations in which full-time students are involved, and that it is less linked to factors in the institutions and more to factors outside of the school environment; for example, to friends, family, or employers (Bean \& Metzner, 1985). In their model, Bean and Metzner foresaw that successful completion or failure of education is caused, particularly, by factors related to previous academic achievements, as well as demographic, cultural, and socio-economic characteristics of the individual.

Despite the adaptation of this model to adult learners, Kember $(1989,1995)$ notes that the difference between adults who are trained in the traditional way, and adults who are learning at a distance, is too big to apply to his model of distance education. Kember (1989) complemented Tinto's model with a new design, which is specially adapted to the conditions in which certain education takes place at a distance.

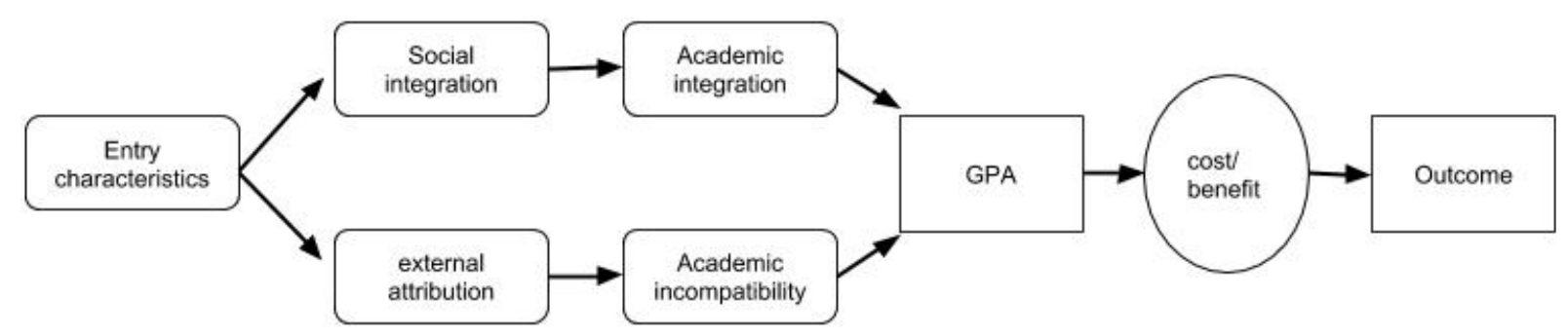

Figure 3. A model of student progress in open learning courses (Kember, 1995) 
Kember (1989) proposed a longitudinal approach to examining dropout rates in distance learning. It highlights the complexity of interactions between factors like family, personal motivation, and capabilities available to complete the program, along with previous achievements and experiences in education and institutional support. Kember assumed that the participants in distance education were employed adults with families. Among the situational factors that affect their schooling, it is particularly important for a participant to take care of their family, work, and study commitments (Kember, 1989), which is a much smaller, if existent, factor for full-time students. Kember also believes that family circumstances, such as age or number of children at school age, housing conditions, or obligations arising out of the profession significantly influence decisions concerning the suspension of each study participant or participants.

Rovai (2003) proposed a "Composite Persistence Model" that builds on Tinto's (1975) "Student Integration Model" and Bean and Metzner's (1985) "Student Attrition Model." His aim was to specifically address the understanding of retention in the context of distance learning, and he claims that distance education students are qualitatively different from face-to-face students in several respects, which need to be considered when trying to understand student retention in a distance education context. Rovai's model differentiates between relevant factors prior to admission and relevant factors after admission, which influence a student's decision about whether to persist or withdraw from study. Relevant factors prior to admission are divided into student characteristics (e.g. gender, age, level of intellectual development, previous academic achievements) and student skills (e.g. Internet skills, time management, and communication), while factors after admission are divided into external factors (e.g. money, obligations at work, family responsibilities) and internal factors (e.g. self-esteem, learning habits, school, and social cohesion).

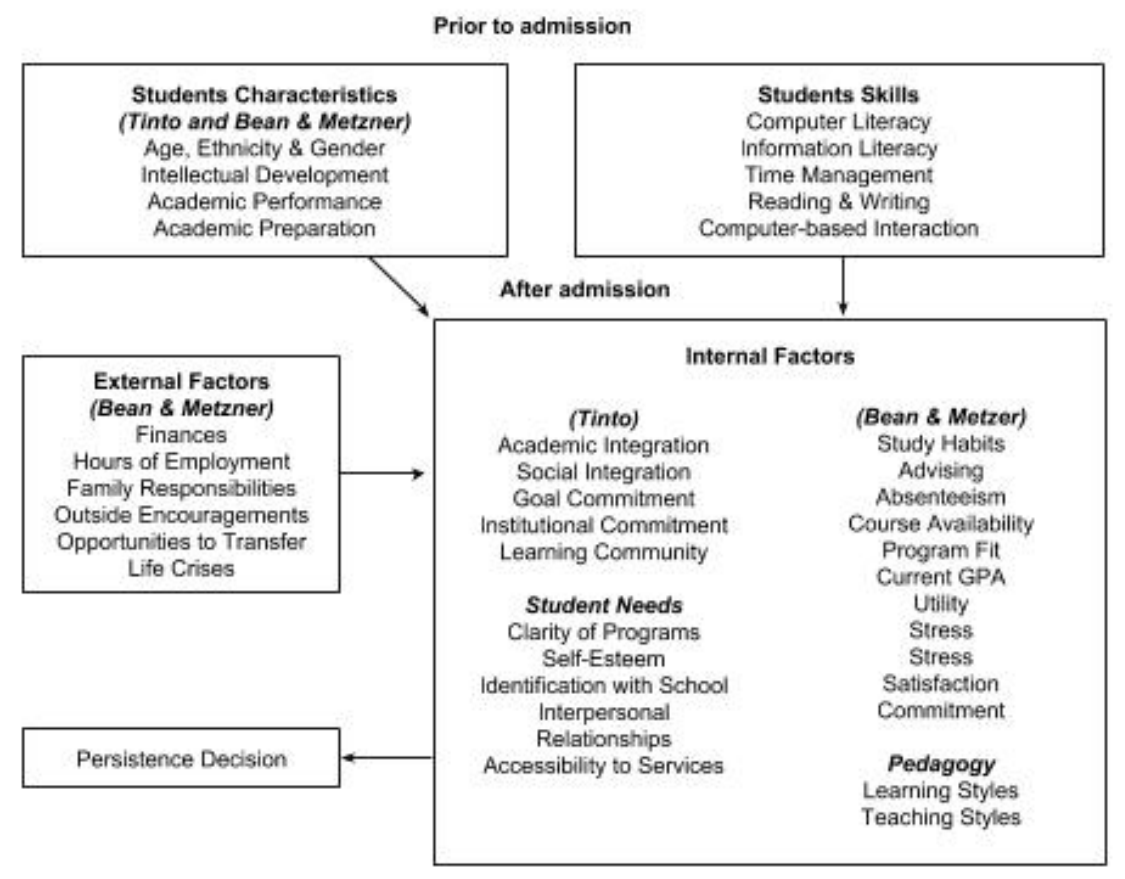

Figure 4. Composite Persistence Model (Rovai, 2003)

More recently, Park (2007) proposed a model to serve as an upgrade to the previous ones, especially the model envisaged by Rovai (2003). She notes that the adequacy of earlier models was verified with very different research approaches, and suggests it changes depending on the empirically observed importance of various factors. In the model, she relativizes the importance of the student's skills and divides the dimensions to those that occur "before" and "during" education (Figure 5). 


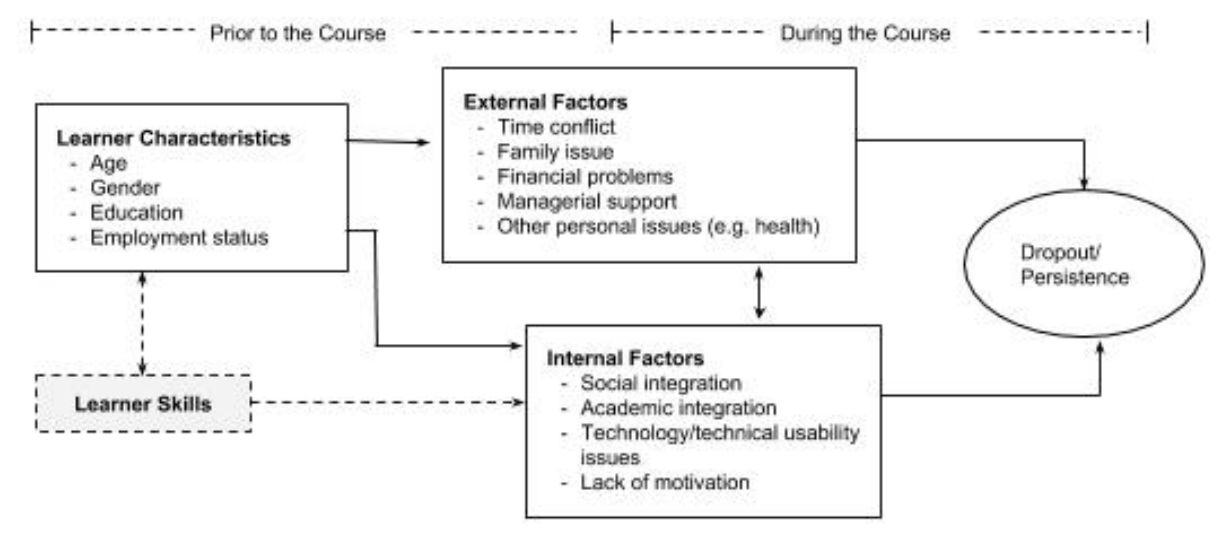

Figure 5. The revised model of dropouts from distance learning in organizations (Park, 2007)

Park and Choi (2009) note that despite a large number of conceptual models, there has not been much research done to empirically confirm the impact of a particular factor in the actual dropout rate from distance education. Park and Choi (2009) conducted a study in which they covered the 147 participants who had completed the training or dropped out from education in one of the programs in the Midwestern college. They have found statistically significant differences between dropout students and successful ones in how they perceived support from family and/or employer, as well as differences in satisfaction and usefulness of the program they attended (Park \& Choi, 2009). The importance of factors in the theoretical model developed by Park (2007) were also tested using logistic regression. It was discovered that the included variables satisfactorily predict a greater or lesser probability of dropout from education (Park \& Choi, 2009).

\section{DISCUSSION}

In the issue of drop outs, educators have two main concerns: how to identify students who drop out from education and which factors will influence drop outs. As we saw from the review of different retention models, these two questions can be answered with two main interpretations. They dictate the specific actions with which teacher or educational institutions can reduce this problem. The first explanation is more sociological, and focuses on trying to identify "objective," situational characteristics, for example previous education, gender, age, income, social status, year of studies, assessments, etc. (e.g. Carroll, $\mathrm{Ng}, \&$ Birch, 2013). The second explanation is concerned with more personal -psychological-characteristics that may affect persistence in the program. In his later work, Tinto (2010) distinguished between "retention" and "persistence." The first term is limited to the perspective of the institution, and its measures to retain students in education. On the other hand, "persistence" is tied to an individual student and his or her motivation to persist in education. As it is obvious from the previous chapters, all presented models are, at their core, interactive- they include both perspectives and the strategies to reduce drop outs and increase retention. This is also confirmed by empirical research (Brewer \& Yucedag-Ozcan, 2013; Yukselturk \& Inan, 2006).

Related to these criteria, Yorke (2004, pp. 23-25) list the following as important determinants of student persistence:

- beliefs about self-efficacy and locus of control;

- targeting;

- practical and emotional intelligence;

- a sense of belonging to a group and educational institutions;

- attitudes;

- ability to effectively manage time and the area of study.

Various factors influence student retention, including perception of learning experiences and relationships. Although many of these factors and models are equally represented, institutions can somewhat control them. 
Tyler-Smith (2006) notes that in the dropout rate of non-traditional students, for first time participants in the program of distance education, influences include sociological, psychological, technical, and cognitive factors. Cognitive load of the participant and the participant's ability to cope are the most important. Students in distance education firstly needs to master the technology, learning environment, a new application, and a new way of communication (Tyler-Smith, 2006, p. 78). Educational organizations sometimes too quickly attribute drop outs to disruption of education, lack of motivation, or skills of the participants. Highly motivated and able participants will learn even under unfavorable conditions. Despite having access to enough suitable teaching materials, most participants will need some support in learning.

In a review of research, we found that the dropout rate in e-learning programs is of greatest importance at the beginning of the program, once the participants have just become acquainted with the virtual learning environment, teachers' requirements, and each other. Gilly Salmon (2004) provides much useful and practical advice in connection with the introduction of the participants to distance education program. She emphasizes the need to limit the information and activities related to the content in the initial stages of the educational program. Instead, teachers should focus on activities that promote the creation of an individual's online identity, design, and integration of learning groups, group setting rules and standards, in order to establish expectations and an understanding of rules relating to online discussions (Salmon, 2004, p. 197). She also recommends the greatest possible simplification of the initial virtual learning environment and the gradual introduction of complexity, which takes place together with the increasing use of the possibilities offered by a single (virtual) learning environment. This can be an effective way to reduce the congestion of the participants in the first stages of learning in the virtual classroom.

Several authors also suggest that the careful preparation of introductory activities in distance education is beneficial for the retention of students (Brewer \& Yucedag-Ozcan, 2013; Gregori, Martínez, \& MoyanoFernández, 2018; Salmon, 2004; Van Ameijde et al., 2016). Introductory workshops, in which the students of distance education encounter a teacher face-to-face, have a very positive effect on the initial readiness and expectations of the participants, which will have all training carried out in the online class. The value of face-to-face meetings with other participants, teachers, and authors of the material is significant, as well as introductory activities taking place in the online classroom-e.g., personal presentation, a salutation, a preliminary discussion on the topic, etc. Thus, the participant is introduced progressively into more complex activities and tasks to be carried out as part of the program in which he/she participates, thereby eliminating the initial negative stereotypes or obstacles that could lead to premature abandonment of the program. Online ice-breakers are also an effective method to promote communication between course participants in a nonthreatening manner (Conrad \& Donaldson, 2011).

The results also show that the reduction in the dropout rate can happen by detecting how much education is useful for the participant. Organizations that are able to motivate participants, develop exciting and stimulating materials, and improve the quality of social interaction between participants and teachers are likely to perform better in reducing dropout rates than institutions that do not put enough effort into highquality pedagogical support. An important factor is also educational support that is given to the participant during the program (Park \& Choi, 2009). The dropout rate can be reduced by appropriate counseling before inclusion in the program (identification of needs and the adequacy of program participants), and by providing adequate, prompt, and efficient counseling during the program. It is also important to create a learning atmosphere that encourages participants to seek professional help and advice from teachers and advisors, and to talk to each other. Taken together, these circumstances create a climate of support, encourage ongoing participation in the learning group, and thus maintain motivation and interest.

One recent publication that lists ten strategies to retain students is authored by Van Ameijde et al. (2016). They recognize that student retention is a complex, multifaceted issue that is the result of many contextual and/or subjective factors. However, they stress that many at-risk students could be motivated to stay the course with design-related aspects. In their model, they focus on aspects of module design that can influence retention. In their view, student retention results from a careful curriculum design that pays attention to Integration, Collaboration, Engagement, Balance, Economics, Reflection, and Gradualism (hence its name, ICEBERG). 


\title{
RECOMMENDATIONS FOR FUTURE RESEARCH
}

The findings of our article improve our understanding of the factors that contribute to academic failures or success in distance education. As evidenced by the reviews of existing models, the drop-out factors in distance education are many, and although some progress has been made in providing feasible solutions to this issue, this phenomenon needs to be analyzed much more deeply. Wider studies should be carried out to gain a better understanding of ways to resolve issues in the field of distance education and an improvement of online classes and curricula that will benefit both pupils and teachers. Therefore, researchers are strongly encouraged to take part in scientific research in which they can study the problem of student retention more closely, using different research methodologies and larger, more diverse study programs patterns.

\section{CONCLUSION}

The research on dropouts from distance education programs is a field that is still evolving. Previous studies and reviews in this area have shown that the models which have studied dropouts in traditional (face-toface) classes are rather deficient and inadequate. Distance education has some distinctiveness that brings new obstacles and new strategies to the fore, which can allow teachers and other educational personnel to promote learning in e-classrooms. Studies show that the measures most important for reducing student dropout rates must be enforced at the beginning of the learning process. A significant amount of new information, new online tools, and hidden features of the virtual learning environment often contribute to high dropout rates in the first few weeks of the program. Support for participants in e-education programs is crucial. Participation in distance education usually requires more motivation and effort from a student, in comparison to the self-motivation required in a face-to-face education. Skills for independent learning are also an essential requirement, but participants have often not developed them throughout the course of their previous education.

Acknowledgements: Author acknowledge the financial support from the Slovenian Research Agency (research core funding No. P5-0174)

\section{BIODATA and CONTACT ADDRESSES of AUTHOR}

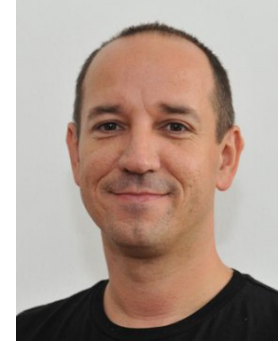

Dr. Marko RADOVAN, is an Associate Professor at the Department of Educational Sciences, University of Ljubljana. He received a master's degree (2003) and a doctoral degree (2009) in Psychology from Faculty of Arts, University of Ljubljana. His main areas of interest are distance education, ICT integration in education, adult learning, and instructional technology. He has published over 30 scientific journal articles, more than 10 book chapters and other national and international articles.

\author{
Marko RADOVAN \\ Address: Department of Educational Sciences, Faculty of Arts, University of Ljubljana \\ Faculty of Arts, Askerceva 2, 1000, Ljubljana, Slovenia \\ Phone: +38612411146 \\ E-mail: marko.radovan@ff.uni-lj.si
}




\section{REFERENCES}

Bawa, P. (2016). Retention in Online Courses: Exploring Issues and Solutions-A Literature Review. SAGE Open, 6(1), 2158244015621777. https://doi.org/10.1177/2158244015621777

Bean, J. P., \& Metzner, B. S. (1985). A Conceptual Model of Nontraditional Undergraduate Student Attrition. Review of Educational Research, 55(4), 485-540.

Benson, S. (2013, August 6). What is Personalized Learning? A Working Draft. Retrieved August 9, 2018, from https://scottebenson.wordpress.com/2013/08/06/what-is-personalized-learning/

Brewer, S. A., \& Yucedag-Ozcan, A. (2013). Educational Persistence: Self-Efficacy and Topics in a College Orientation Course. Journal of College Student Retention: Research, Theory \& Practice, 14(4), 451-465. https://doi.org/10.2190/CS.14.4.B

Carr, S. (2000). As Distance Education Comes of Age, the Challenge Is Keeping the Students. Chronicle of Higher Education, 46(23), 39-41.

Carroll, D., Ng, E., \& Birch, D. (2013). Strategies to Improve Retention of Postgraduate Business Students in Distance Education Courses: An Australian Case. Turkish Online Journal of Distance Education, 14(1), 140-153.

Conrad, R.-M., \& Donaldson, J. A. (2011). Engaging the Online Learner: Activities and Resources for Creative Instruction (Updated edition). San Francisco: Jossey-Bass.

Diaz, D. P. (2002). Online drop rates revisited. The Technology Source, (1). Retrieved from http://technologysource.org/article/online_drop_rates_revisited/

Docebo. (2018). eLearning Trends for 2018. London; Toronto; Athens: Docebo Inc. Retrieved from https:// www.docebo.com/resource/whitepaper-elearning-trends-2018/

Eraut, M. (2009). Transfer of knowledge between education and workplace settings. In H. Daniels, H. Lauder, \& J. Porter (Eds.), Knowledge, values, and educational policy: a critical perspective (pp. 65-84). London; New York, NY: Routledge.

Flood, J. (2002). Read all about it: online learning facing 80\% attrition rates. The Turkish Online Journal of Distance Education, 3(2). Retrieved from http://tojde.anadolu.edu.tr/makale_goster.php?id=48

Gomez-Zermeno, M. G., \& Aleman de La Garza, L. (2016). Research Analysis on MOOC Course Dropout and Retention Rates. Turkish Online Journal of Distance Education, 17(2), 3-14.

Gregori, P., Martínez, V., \& Moyano-Fernández, J. J. (2018). Basic actions to reduce dropout rates in distance learning. Evaluation and Program Planning, 66, 48-52. https://doi.org/10/gcr4b7

Herbert, M. (2006). Staying the Course: A Study in Online Student Satisfaction and Retention. Online Journal of Distance Learning Administration, 9(4). Retrieved from https://www.westga.edu/ - distance/ojdla/winter94/herbert94.htm

Keegan, D. (1996). Foundations of distance education (3rd ed.). London: Routledge.

Kember, D. (1989). A Longitudinal-Process Model of Drop-Out from Distance Education. The Journal of Higher Education, 60(3), 278-301. https://doi.org/10.1080/00221546.1989.11775036

Kember, D. (1995). Open learning courses for adults: A model of student progress. Englewood Cliffs, NJ: Educational Technology Publications.

Lee, E., Pate, J. A., \& Cozart, D. (2015). Autonomy Support for Online Students. TechTrends, 59(4), 54-61. https://doi.org/10.1007/S11528-015-0871-9

Liu, D., Huang, R., \& Wosinski, M. (2017). Smart Learning in Corporate University. In D. Liu, R. Huang, $\&$ M. Wosinski (Eds.), Smart Learning in Smart Cities (pp. 119-145). Singapore: Springer Singapore. https://doi.org/10.1007/978-981-10-4343-7_6

Makovec, D. (2018). The teacher's role and professional development. International Journal of Cognitive Research in Science Engineering and Education, 6(2), 33-45. https://doi.org/10.5937/ ijcrsee1802033M 
Marland, P. (1997). Towards more effective open and distance teaching. London: Kogan Page.

OECD. (2017). Who is expected to graduate from tertiary education? In Education at a Glance 2017 (pp. 64-74). OECD Publishing. https://doi.org/10.1787/eag-2017-en

Park, J.-H. (2007). Factors Related to Learner Dropout in Online Learning. Presented at the International Research Conference in The Americas of the Academy of Human Resource Development, Indianapolis, IN, Feb 28-Mar 4, 2007.

Park, J.-H., \& Choi, H. J. (2009). Factors Influencing Adult Learners' Decision to Drop Out or Persist in Online Learning. Journal of Educational Technology \& Society, 12(4), 207-217.

Parker, A. (1999). A study of variables That predict dropout from distance education. International Journal of Educational Technology, 1(2). Retrieved from http://ascilite.org/archived-journals/ijet/v1n2/ parker/

Peters, O. (2001). Learning and teaching in distance education: Pedagogical analyses and interpretations in an international perspective. New York: Routledge.

Rovai, A. P. (2003). In search of higher persistence rates in distance education online programs. The Internet and Higher Education, 6(1), 1-16. https://doi.org/10.1016/S1096-7516(02)00158-6

Salmon, G. (2004). E-moderating: The key to teaching and learning online. Routledge.

Simonson, M. R., Smaldino, S. E., \& Zvacek, S. (2015). Teaching and learning at a distance: foundations of distance education (Sixth edition). Charlotte, North Carolina: Information Age Publishing.

Simpson, O. (2003). Student retention in online, open, and distance learning. London and Sterling, VA: Kogan Page.

Simpson, O. (2004). The impact on retention of interventions to support distance learning students. Open Learning, 19(1), 79-95.

Simpson, O. (2013). Student retention in distance education: are we failing our students? Open Learning: The Journal of Open, Distance and e-Learning, 28(2), 105-119. https://doi.org/10.1080/0268051 3.2013.847363

Spady, W. G. (1971). Dropouts from higher education: Toward an empirical model. Interchange, 2(3), 3862. https://doi.org/10/dzrdk3

Spector, J. M. (2014). Conceptualizing the emerging field of smart learning environments. Smart Learning Environments, 1(1), 2. https://doi.org/10.1186/S40561-014-0002-7

Tait, A., \& Mills, R. (1999). The convergence of distance and conventional education: Patterns of flexibility for the individual learner. In A. Tait \& R. Mills, The convergence of distance and conventional education: Patterns of flexibility for the individual learner (pp. 1-4). New York: Routledge.

Taylor, J. C. (2001). Fifth generation distance education. E-Journal of Instructional Science and Technology (e-JIST), 4(1), 1-14.

Taylor, James C. (1995). Distance education technologies: The fourth generation. Australian Journal of Educational Technology, 11(2), 1-7.

Tinto, V. (1975). Dropout from higher education: A theoretical synthesis of recent research. Review of Educational Research, 45(1), 89.

Tinto, V., \& Smart, J. C. (2010). From Theory to Action: Exploring the Institutional Conditions for Student Retention. In Higher Education: Handbook of Theory and Research (Vol. 25, pp. 51-89). Dordrecht: Springer.

Tinto, V. (2006). Research and Practice of Student Retention: What Next? Journal of College Student Retention: Research, Theory \& Practice, 8(1), 1-19. https://doi.org/10/bct36r

Tyler-Smith, K. (2006). Early attrition among first time elearners: A review of factors that contribute to drop-out, withdrawal and non-completion rates of adult learners undertaking elearning programmes. Journal of Online Learning and Teaching, 2(2), 73-85. 
Van Ameijde, J., Weller, M., \& Cross, S. (2016). Quality Enhancement Report: Designing for Student Retention - The ICEBERG Model and Key Design Tips (p. 40). Milton Keynes, UK: The Open University.

Yorke, M. (2004). Retention, persistence and success in on-campus higher education, and their enhancement in open and distance learning. Open Learning, 19(1), 19-32.

Yukselturk, E., \& Inan, F. A. (2006). Examining the Factors Affecting Student Dropout in an Online Learning Environment. Turkish Online Journal of Distance Education, 7(3), 76-88. 